\title{
O pluralismo hoje: sobre a atualidade de Antonio Candido (1918-2017)
}

Pluralism today: about the up to dateness of Antonio Candido (1918-2017)

\section{Mariza Peirano}

\section{(2) OpenEdition}

12 Journals

Edição electrónica

URL: https://journals.openedition.org/aa/2511

DOI: 10.4000/aa.2511

ISSN: 2357-738X

Editora

Programa de Pós-Graduação em Antropologia Social (UnB)

\section{Edição impressa}

Data de publição: 1 dezembro 2017

Paginação: 385-393

ISSN: 0102-4302

\section{Refêrencia eletrónica}

Mariza Peirano, «O pluralismo hoje: sobre a atualidade de Antonio Candido (1918-2017)», Anuário Antropológico [Online], v.42 n.2 | 2017, posto online no dia 12 junho 2018, consultado o 18 maio 2021. URL: http://journals.openedition.org/aa/2511 ; DOI: https://doi.org/10.4000/aa.2511

\section{(c) $\underset{\mathrm{EY} \text { NG } \mathrm{ND}}{(\mathrm{O})}$}

Anuário Antropológico is licensed under a Creative Commons Atribuição-Uso Não-Comercial-Proibição de realização de Obras Derivadas 4.0 International. 


\section{O pluralismo hoje: sobre a atualidade de Antonio Candido (1918-2017)}

Mariza Peirano

É de Antonio Candido a ideia de que "um homem só nos é conhecido quando morre”. A morte, ele explica, é um limite sem retorno. O romancista, ou o artista em geral, constrói personagens de ficção coerentes, muito mais coesos e satisfatórios do que o conhecimento fragmentário que temos dos seres vivos, sempre menos lógicos e mais sujeitos às eventualidades. ${ }^{1}$ Talvez por este motivo, Antonio Candido não se apresentava como um autor completo; ao contrário, seus próprios ímpetos o surpreendiam, porque se considerava uma pessoa de poucos arrebatamentos, e ele os deixava transparecer sem racionalizá-los.

Considerado o grande nome da crítica literária no Brasil, Antonio Candido foi reconhecido também como sociólogo, professor e escritor, em todos os campos premiado. Embora a antropologia tenha sido central na sua formaçáo, a ponto de sua tese de doutorado, Os parceiros do Rio Bonito, haver sido penalizada por Roger Bastide com um 9 por não ser pura sociologia, sua contribuição na área não é muito comentada. É possível que exatamente por esta razáo Antonio Candido tenha se entusiasmado quando, como antropóloga em formação, pedi a ele que me concedesse uma entrevista no final de 1978. Ele tinha 60 anos entáo.

Antonio Candido concedeu muitas entrevistas ao longo da vida, tendo recontado inúmeras vezes sua trajetória. ${ }^{2}$ Mas, como sabemos, há várias maneiras de relatar o passado ou reviver momentos especiais. Estimulado a narrar o período em que se formou e as opçóes que entáo estavam abertas, naturalmente tendo em vista interesses vindos à tona pelas minhas perguntas, Antonio Candido foi generoso ao relatar sua iniciação nas ciências sociais. A mim, interessava especialmente como, de um tronco comum no início dos anos 1930 em São Paulo, tanto na Universidade de Sáo Paulo (USP) quanto na Escola Livre de Sociologia e Política, as disciplinas das ciências sociais, como hoje as conhecemos, foram se formatando conceitual e institucionalmente. Antonio Candido captou de imediato a questáo que enunciei ainda timidamente. E respondeu combinando o clima da época com sua trajetória particular, incluindo detalhes de família, 
aspectos do seu temperamento, professores, colegas e alunos. Não por acaso, quando publiquei uma coletânea com capítulos da tese, o primeiro foi dedicado a mapear as oportunidades que se abriram pelo pluralismo - termo seu - que dominava o cenário acadêmico da USP quando se formou.

Em entrevistas, eu nunca havia encontrado um orador tão refinado - suas palavras podiam ser transcritas literalmente, sem qualquer edição; tão modesto com receio de parecer arrogante, enfatizava a postura oposta na imagem do jovem um pouco atrapalhado; tão franco - confissóes que geralmente guardamos, ele as expunha sem pudor; com tanto equilíbrio - de seus colegas, só tinha palavras elogiosas; e, além de tudo, tão gentil - ao fim de duas horas, descobri que havia se preparado para me oferecer um cálice de vinho do porto em sua casa em São Paulo para encerrar nossa conversa. Uma linda entrevista; um exemplo de espontaneidade perspicaz que só os muito confiantes possuem.

Antonio Candido de Mello e Souza nasceu no Rio de Janeiro, mas sentia que era uma pessoa do interior, devido ao fato de sua família ter raízes rurais. Seu avô foi fazendeiro em Minas, e também seu pai tinha terras em Cássia, Passos, no sudoeste do estado. Antonio Candido via-se como parte de uma família antiga de criadores de gado. Na geração anterior, o pai foi o primeiro a fazer curso superior, de medicina (os tios mais novos se urbanizaram logo). Portanto, interessar-se por cultura caipira, que, mais tarde, resultou em Os parceiros do Rio Bonito, não foi acidental. Foi fruto de uma vivência intensa na infância. Depois de anos em Poços de Caldas, onde o pai havia organizado o setor de reumatologia, em São Paulo seu interesse se dirigiu à literatura e, entre as ciências sociais, à antropologia. Os Parceiros resultou de uma aversão à sociologia do tipo ortodoxo, mas que ensinou durante 16 anos na USP. Em contraste, entusiasmava-se pelo "fundo poético acentuado" da antropologia. Assim, leu as monografias clássicas de Malinowski, de Radcliffe-Brown, de Evans-Pritchard, acreditando muito em suas intuiçôes, já que era "muito ruim para método". Ironizava: "quando a minha observação coincidia com as minhas intuições, eu achava que o método estava certo...”3 Em 1978, lamentava que, na época de sua formação, não houvesse cursos monográficos em sociologia. Tudo isso fazia que visse sua carreira na sociologia como provisória. Sentia que ministrava os cursos sem grande paixáo, e repetia o que era exigido de forma mais ou menos rígida: método, técnicas, classes sociais, grupos sociais. Mas o fazia por senso de dever.

Este senso de dever foi uma constante em sua vida, levando-o a se considerar "um desertor" por não ter seguido o desejo do pai de ser médico, conforme a 
tradição da família. Foi assim, portanto, que o episódio em que se inscreveu para a Faculdade de Filosofia, e só depois avisou o pai, tornou-se um de seus poucos gestos de rompante e de independência. Para sua alegria, o pai não foi intransigente, como Antonio Candido temia, mas pediu que o filho fizesse também o curso de direito, "para não morrer de fome". O resultado é que os dois cursos foram realizados simultaneamente.

Simultaneamente também, manteve durante muito tempo as atividades de sociólogo e de crítico literário. Literatura foi um interesse constante, mas, como havia feito sociologia na Faculdade de Filosofia, tornando-se depois professor, afastou-se quando defendeu a tese de sociologia: professor poderia ser, mas sociólogo não era.

Muitos anos depois, Antonio Candido dividiu sua trajetória como autor em três fases. Cada uma correspondia a uma década. Tratava-se de uma simplificação geral e esquemática, mostrando uma coerência das ideias que elas não tiveram, como ressaltou (Candido, 1974:3-4). A primeira fase, da década de 1940, exemplificava a preocupaçáo com a busca de causas, correspondendo a uma vertente positivista do marxismo. Desta fase, considerava a Introdução ao método crítico de Silvio Romero (1945) seu trabalho principal. Superada, a fase seguinte representou uma guinada oposta, mostrando, de um lado, a influência da antropologia inglesa, notadamente de Malinowski (The argonauts of the Western Pacific) e RadcliffeBrown (The Andaman islanders); e, de outro, as ideias críticas de T. S. Eliot e o new criticism norte-americano. Estas influências refletiram-se em Os parceiros do Rio Bonito (1954) e em Formação da literatura brasileira (1959) pela preocupação com a pertinência dos traços de um determinado sistema e o desejo de ver um sentido diacrônico combinado "ao respeito pela visão sincrônica". Nos anos 1960, Antonio Candido indagava "como a estrutura se estrutura", isto é, interessava-lhe náo mais tanto o condicionamento quanto o próprio sistema, em uma fórmula pela qual "o externo se torna interno". Esta é uma das preocupaçóes centrais do livro Literatura e sociedade (1965). ${ }^{4}$

Em que sentido a obra de Antonio Candido pode inspirar cientistas sociais em geral e, em particular, antropólogos? Os parceiros, Formaçâo da literatura brasileira e Literatura e sociedade podem nos fascinar, quando não nos orientar, em primeiro lugar, por suas premissas "pluralistas", no dizer do autor. Esse pluralismo, que Antonio Candido considerou marcante em sua formaçáo, devia-se à influência 
predominante da sociologia durkheimiana no início da Faculdade de Filosofia; esta era uma espécie de cânone da USP, trazido pelos professores da Missão Francesa que haviam sido convidados para preencher os principais postos da nova Faculdade (Peirano, 1981:cap. 2). Mas ela já tinha raízes no Brasil, por exemplo, na orientaçáo pessoal de Fernando de Azevedo (de quem, anos mais tarde, seria assistente). Antonio Candido lembra que Durkheim conduzia muito para a antropologia, não apenas devido ao grande livro As formas elementares da vida religiosa, mas pela atividade da revista L'Année Sociologique, por meio de Mauss, Halbwachs e outros discípulos. Na USP, a tendência pluralista incluía, ao lado de Durkheim, um marxismo muito aberto, ensinado por um influente professor de filosofia, Jean Maugüé. Completava o quadro a orientação para a pesquisa, inspirada na antropologia inglesa e na americana. Em suma, "os franceses, de um lado, a linha oficial da USP; ao lado, discretamente, um certo marxismo flexível; e de outro, a entrada da etnologia e da antropologia cultural de influência de Boas e de Lowie". Este foi o quadro de referência na época de sua formaçáo (Peirano, 1992:cap. 1).

Mais tarde, chegaria o momento "inevitável e conveniente" da separação clara das disciplinas, ainda que nunca eliminando totalmente o pluralismo que marcara o momento de gênese das ciências sociais e sua institucionalização. A distinção entre as ciências sociais foi gradual e deu-se mais por um processo de incorporação do que pela subtração de influências, guiado pelo necessário comprometimento social e político do cientista social. A pertinência desse trânsito entre fronteiras disciplinares mantém-se até hoje, tanto nos programas de graduação na área quanto nos vários Institutos de Ciências Sociais em todo o país, incluindo naturalmente os encontros anuais da Associação Nacional de Pós-Graduação e Pesquisa em Ciências Sociais (ANPOCS), núcleos de pesquisa e seminários ocasionais. É como resultado complexo dessa herança histórica que, em 1974, Antonio Candido assim se autodefiniu: "não sou um teórico da literatura, mas um crítico literário que ensina Teoria. Por isso, tendo a ver [a literatura] como auxiliar da crítica; quase como uma teoria da análise" (Candido, 1974:9, ênfase minha). Definição densa, e sempre atual.

Ao colocar o termo "teoria" em pauta, a referência implícita a Florestan Fernandes é inevitável, já que foram, ao longo da vida, "outros” mútuos. Para Antonio Candido, foi Florestan quem teve historicamente razão ao lutar contra o ensaísmo, contra o diletantismo e pela defesa do rigor científico. Se era preciso começar a definir as disciplinas das ciências sociais, Florestan estabeleceu os 
princípios para demarcar o campo da sociologia, especialmente seus padróes teóricos combinados ao engajamento social. Amigos e companheiros, ambos tinham preocupaçóes em comum, talvez a principal delas a procura de uma visão ao mesmo tempo estática e dinâmica da sociedade. Mas cada um tomou um caminho: para Antonio Candido, Florestan extraiu de Sáo Paulo tudo que a cidade podia dar em matéria de formação sociológica e antropológica; "um menino de 25 anos", por exemplo, teve a coragem de analisar a organizaçáo social tupinambá, antes considerada impossível. Florestan tinha "uma inteligência absolutamente privilegiada, genial, fora do comum”. Modesto, Antonio Candido diz que se contentava em seguir a intuição, com uma vocaçáo muito mais para ensaísta, isto é, "ensaiar, repetir, debater com a realidade e chegar à conclusão assim que os dados fossem coerentes". Segundo ele, seu mérito consistia em "preservar e não deixar perder uma tradição brasileira do ensaio humanístico e sensível, de tipo literário". Assim, obsessôes comuns - combinar a sociologia acadêmica com uma visão marxista de que a sociedade é um processo constante - tiveram soluçôes diversas. A esse propósito, conclui, "nós somos dois temperamentos diametralmente opostos e duas afetividades perfeitamente identificadas".

Temperamentos opostos e opçôes diferentes aos desafios intelectuais, não obstante, do ângulo dos ideais comuns, Antonio Candido se via como muito cético e percebia Florestan como muito crente: "eu sou mais a favor das transformaçóes graduais, da luta do cotidiano, enquanto [Florestan] acha mais a possibilidade das soluçóes revolucionárias”. A influência de ambos é atestada pelo sociólogo Fernando Henrique Cardoso, quando notou que sua geração teve como base "o rigoroso método científico e a disciplina mental de Florestan Fernandes e, como ideal, o discreto charme do ensaísmo de Os parceiros do Rio Bonito" (1972 apud Candido). Se Florestan foi o grande nome das ciências sociais institucionalizadas, aquele que reanalisou o material seiscentista dos cronistas e que criou uma "escola", Antonio Candido preservou e espalhou a marca da antropologia nas ciências sociais em geral.

Alguns poucos sinais são reveladores. É inegável, por exemplo, o caráter antropológico de Os parceiros, introduzindo de maneira sensível, no cenário brasileiro, as monografias claramente investidas de preocupação política. Embora outras monografias tenham sido produzidas na época, Os parceiros reflete o engajamento do autor. Mas não fica aí sua contribuição antropológica. Ela se prolonga em $A$ formação da literatura brasileira, escrita na mesma época. A distinçáo fundamental que propóe entre "manifestaçôes" de literatura e "literatura" propriamente dita leva em conta a eficácia social da relação artistaobra-público, sem hierarquizá-las previamente a partir de uma noção não 
analítica. Já Literatura e sociedade é plena de exemplos etnográficos (Malinowski, Audrey Richards, Evans-Pritchard) entremeados à literatura ocidental clássica e moderna brasileira (Homero, Baudelaire, Mário de Andrade, Machado de Assis) em exercícios de análise primorosos. Não se tratava apenas da introdução de ilustraçóes de "sociedades primitivas", mas de empenho teórico na construção dos próprios exercícios comparativos. E, por seu significado no contexto brasileiro, é imprescindível mencionar como Antonio Candido situa o papel da literatura entre nós: "diferentemente do que sucede em outros países, a literatura tem sido aqui, mais do que a filosofia e as ciências humanas, o fenômeno central da vida do espírito" (1975:119), proposta fundamental para analisar e apreciar as várias manifestações da nossa vida intelectual e acadêmica.

Por último, cabe notar que é Antonio Candido quem propóe que um passo fundamental para o Brasil ser uma "variedade" da literatura mundial é a criação de trabalhos de primeira ordem influenciados não apenas por modelos estrangeiros imediatos, mas por exemplos nacionais anteriores (1987:153). ${ }^{6}$ Certamente essa percepção pode ser expandida para além da literatura.

Impressionado com a atualidade do trabalho de Antonio Candido, o sociólogo Howard Becker decidiu traduzir vários de seus artigos e reuni-los no livro On literature and society, editado pela Princeton University Press em 1995. Em sua introdução, Becker ressalta como, com raízes fincadas na história e vida do Brasil, Antonio Candido esteve sempre envolvido com o mundo contemporâneo. Chamando-o de "a world writer", revela que Antonio Candido escreve sobre a literatura mundial ocidental incluindo a literatura de antigas colônias. Nota que os tópicos de seu interesse incluem vingança, catástrofe, classe, mudança social e engajamento político, e ressalta que seu domínio de várias línguas - além do português, espanhol, francês, italiano e inglês - o torna apto para embarcar em uma larga comparaçáo, raramente encontrada entre críticos contemporâneos. Acrescenta: "não apenas na literatura, mas em filme, teatro e outras artes" (Becker, 1995:xxi). ${ }^{7}$ E conclui:

Candido traz para a interlocução mundial um ponto de vista que, enraizado na experiência do seu país, em sua literatura, em sua história e em seus problemas sociais, oferece novas perspectivas sobre a relação da literatura com a sociedade. Ele não aplica as perspectivas já desenvolvidas da comunidade intelectual ocidental a algum material novo simplesmente, ou mostra que os latinoamericanos também podem dominar esses mesmos métodos. Em vez disso, [...] introduz algo novo, algo que o resto da comunidade intelectual agora pode 
aproveitar e usar, algo que enriquece a bagagem conceitual comum, que decorre da mistura única de um conhecimento da literatura mundial e da situação de um país que é descendente intelectual [...] do pensamento europeu contemporâneo (1995:xxii, tradução livre). ${ }^{8}$

Como faço aqui, Becker fecha sua introdução citando textualmente Antonio Candido, quando este insiste no estabelecimento de linhagens nacionais e causalidades internas para melhor aproveitar os estímulos de outras culturas:

um estágio fundamental na superação da dependência é a capacidade de produzir obras de primeira ordem, influenciada, não por modelos estrangeiros imediatos, mas por exemplos nacionais anteriores. Isto significa o estabelecimento do que se poderia chamar um pouco mecanicamente de causalidade interna, que torna inclusive mais fecundos os empréstimos tomados às outras culturas (Candido, 1987:153).

Tenho o costume de usar a internet para ver e ouvir algumas palestras às quais não tive a oportunidade de estar presente. Em uma dessas ocasióes, ainda em 2017, surpreendi-me com o diálogo entre um crítico literário/músico e um antropólogo em torno de Oswald de Andrade, Clarice Lispector e Guimaráes Rosa, no qual a literatura participava da intimidade intelectual de ambos. Um deles havia sido orientado por Antonio Candido; o outro havia proposto uma abordagem alternativa à análise empreendida por Florestan Fernandes na sua apreensão da vingança tupinambá. Naquele momento mágico, passadas geraçóes, o YouTube parecia mostrar que Antonio Candido e Florestan Fernandes voltavam a se encontrar, deixando visível aquele processo de causalidade interna em que se combinam diálogos mundiais com tradiçôes locais. Confirmava-se também a permanência do vigoroso pluralismo que Antonio Candido retrata como dominante no início das ciências sociais e, mais ainda, o papel da literatura na nossa vida intelectual. ${ }^{9}$ Haveria melhor reconhecimento do seu legado?

Recebido em 05/02/2018

Aprovado em 06/02/2018

Mariza Peirano é Pesquisadora Colaboradora Sênior do Departamento de Antropologia da Universidade de Brasília.

Homepage: <http://www.marizapeirano.com.br> 


\section{Notas}

1. Ver Candido (1976:64) para a diferença entre a personagem de ficção e os seres vivos.

2. Entre elas, Candido (1974), Velho e Leite (1993) e Pontes (2001). Para uma lista de entrevistas, ver Jackson (2002:117). A entrevista que me concedeu pode ser acessada em http://www.marizapeirano.com.br/entrevistas/antonio_candido.html.

3. Todas as citaçôes sem referência de fonte correspondem à entrevista que Antonio Candido me concedeu em 1978 (Candido, 1978).

4. A Wikipedia compilou uma lista das principais obras de Antonio Candido. Ver Referências para link.

5. Aqui reconheço a influência de Marcel Mauss, quando postula que "só há magia quando esta é reconhecida socialmente". A mesma influência pode ser identificada em Peirano (1981).

6. Antonio Candido usa o termo "variedade" neste artigo, inicialmente escrito em 1969, para propósito semelhante ao que, anos mais tarde, Louis Dumont usaria para discutir "variantes" nacionais da ideologia moderna (1994, 1a. Parte). Mas, enquanto Dumont está interessado nos processos de aculturaçáo da ideologia moderna em contextos nacionais, o objetivo de Antonio Candido é o de indicar o bom caminho para que a literatura brasileira esteja entre as mundiais.

7. Embora o volume editado por Becker tenha título semelhante ao livro Literatura e sociedade (Candido, 2000), os capítulos são diferentes. Sobre as capas produzidas nas ediçóes de 1995 e 2016, é de notar o destaque maior do nome de Antonio Candido na edição mais recente, talvez um reconhecimento da crescente importância do autor para o público que lê em inglês.

8. No original: "Candido brings to the world conversation a point of view that, rooted in the experience of his country, in its literature, its history, and its social problems, provides new perspectives on literature and its relation to society. He does not just apply the already developed perspectives of the Western intellectual community to some new material, or show that Latin Americans too can master these methods. Rather [...] he introduces something new, something the rest of that community can now take up and use, something that enriches the common conceptual stock, that arises from his unique mixing of a knowledge of the world's literature and the situation of a country that is the intellectual descendant [...] of contemporary European thought".

9. O diálogo que menciono refere-se ao belo comentário de José Miguel Wisnik à homenagem que o Sesc em Sáo Paulo dedicou ao trabalho de Eduardo Viveiros de Castro entre os Araweté. Ver https://www.youtube.com/watch?v=5erXGRgfZF4 a partir de 1:08:30. 


\section{Referências}

BECKER, Howard. 1995. Introduction. In: Antonio Candido. On literature and society. Princeton: Princeton University Press.

CANDIDO [DE MELLO E SOUZA], Antonio. 2011. Entrevista. Trans-Form-Ação, 34(ed. esp.):3-13. Publicado originalmente em 1974.

_. 1975. Literatura e sociedade. São Paulo: Cia. Editora Nacional.

. 1976. A personagem do romance. In: Antonio Candido et al. A personagem de ficção. São Paulo: Perspectiva. pp. 51-80.

. 1978. Entrevista a Mariza Peirano. Não publicada. Disponível em: http:// www.marizapeirano.com/entrevistas/antonio_candido/html. Acesso em: 25/1/2018.

. 1987. A educação pela noite \& outros ensaios. São Paulo: Ática.

1995. On literature and society (editado, traduzido e com introdução de Howard Becker). Princeton: Princeton University Press.

CARDOSO, Fernando Henrique. 1972. O modelo político brasileiro. São Paulo: Difusão Europeia do Livro.

DUMONT, Louis. 1994. German ideology: from France to Germany and back. Chicago: University of Chicago Press.

JACKSON, Luiz Carlos. 2002. A tradição esquecida: os parceiros de Rio Bonito e a sociologia de Antonio Candido. Belo Horizonte: Ed. UFMG; São Paulo: Fapesp.

PEIRANO, Mariza. 1981. The anthropology of anthropology. the Brazilian case. Ph.D. dissertation, Harvard University.

. 1992. Uma antropologia no plural: três experiências contemporâneas. Brasília:

Universidade de Brasília.

PONTES, Heloísa. 2001. Entrevista com Antonio Candido. Revista Brasileira de Ciências Sociais, 16(47):5-30.

VELHO, Gilberto \& LEITE, Yonne. 1993. Entrevista com Antonio Candido. Ciência Hoje 16(91):28-40.

Wikipedia. Antonio Candido. Disponível em: https://pt.wikipedia.org/wiki/Antonio_ Candido. Acesso em: 25/1/2018. 